processes for evidence of library involvement in the teaching/learning process.

The groups then divided; there were two sessions for the library directors. In one session, Stanton Biddle, Baruch College, described the ACRL University Library Standards for the participants. These standards, plus those for college libraries and two-year institutions and information about the Output Measures Manual, were included in the packets distributed. He stressed the change in emphasis from quantitative to qualitative standards and the need to focus on the meaning of numbers, rather than see them as an absolute. All data must be reconciled with the mission, goals and objectives. He emphasized that the purpose of the site visit is to verify the accuracy of the self-study and to gain a better understanding of the environment.

In the other session, Marilyn Lutzker, John Jay College of Criminal Justice, offered an approach for evaluators as they consider bibliographic instruction programs in their site visits. She suggested they look at the school and weigh the effect of the program on the overall institution. She suggested four methods to use in the evaluation: the self-study, the library's statement of objectives, the examination of syllabi and course outlines, and discussions with faculty, administrators, and stu-

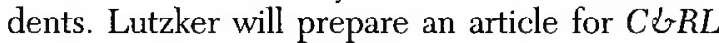
News on this topic in the near future.

Simmons has also accepted an invitation for the Commission to be a member of the ALA-spearheaded National Forum on Information Literacy.

\title{
Educational roles for academic
}

\section{libraries}

\author{
Prepared by the BIS Think Tank
}

Betsy Baker (chair), Beth Sandore, Mary Ellen Larson, Randy Hensley

\section{The ACRL/BIS Think Tank defines the state-of-the-art and prepares an agenda for the future.}

\section{$\mathbf{T}$}

he Bibliographic Instruction Section sponsored its first Think Tank in 1981. A group of six recognized leaders in the area of bibliographic instruction was identified by a BIS planning committee. This early Think Tank of 1981 was charged with several responsibilities: 1 ) identifying the key issues shaping the future of $\mathrm{BI} ; 2$ ) recommending a program of research and action to enable the profession to overcome obstacles and seize opportunities related to $\mathrm{BI}$; 3) stimulating professional discourse. The results of these deliberations outlined an agenda for the 1980s that significantly advanced BI and has served as a focus for much BIS effort over the past decade. The reader is referred to "Think Tank Recommendations for Bibliographic Instruction," College \& Research Libraries News 42 (1981): 396, for further review of the 1981 Think Tank.

Much of the progress in the educational efforts of academic libraries in recent years can be traced to that first Think Tank. Yet, the changes affecting libraries and their institutional constituencies have been equally profound. The ensuing decade since the first Think Tank has seen the widespread move 


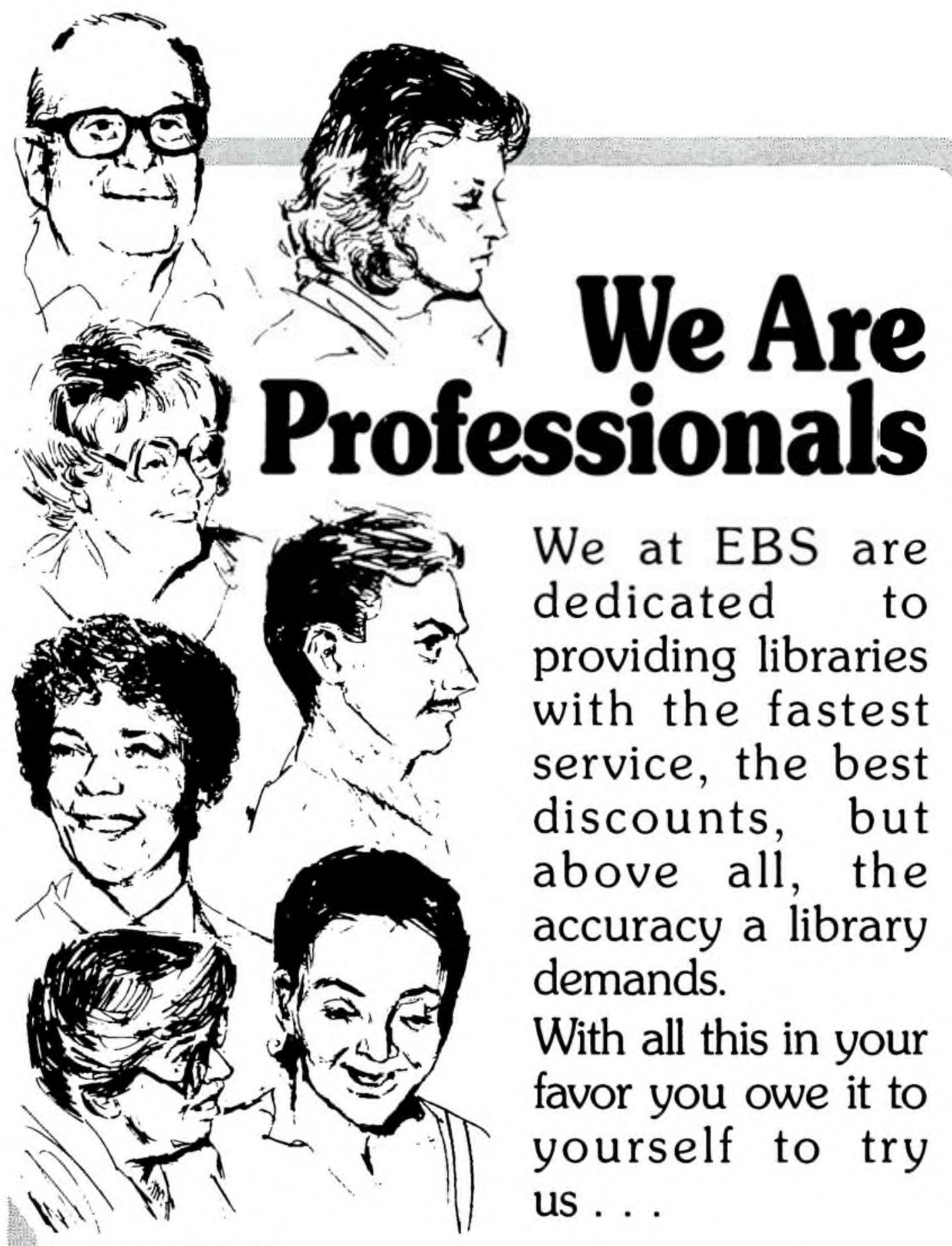

IIIIIIIIIIII

\begin{tabular}{l|lll}
\hline E & B & E.B.S. BOOK SERVICE \\
\hline
\end{tabular} 
to online information retrieval systems, fiscal retrenchment, changes in the demographics of users, and new administrative structures for libraries and other information services. In light of the dramatic changes that occurred since the first Think Tank, and in anticipation that the trends affecting academic libraries are leading to new educational opportunities for librarians, a second Think Tank was recommended by the BIS Executive Committee as a dynamic mechanism for exploring future directions both in the discipline and for the Bibliographic Instruction Section of ACRL. Through the sponsorship of ACRL's Special Grants funding, the second Think Tank was held in Dallas, Texas, June 22-23, 1989, immediately preceding the 1989 ALA Annual Conference.

The BIS Executive Committee appointed a Think Tank Steering Committee, chaired by Betsy Baker, to plan and coordinate this event. Members of the committee included Debbie Campana (Northwestern University), Melanie Dodson (New York University), Randall Hensley (University of Washington), Mary Ellen Larson (Pennsylvania State University), and Beth Sandore (University of Illinois).

\section{Think Tank Two: Setting the stage}

The first Think Tank's approach was to identify leaders within the field to suggest a BI agenda for the 1980s. The second Think Tank focused on gauging what breakthrough issues are occurring in the field that directly concern BI and merit widespread consideration.

The second Think Tank addressed these issues: 1) assessing the state-of-the-art of $\mathrm{BI} ; 2$ ) anticipating the evolution of new service roles to effectively meet the needs of the academic community; 3 ) and identifying areas for concerted effort for the future. The intention was to gather individuals who are strong in the profession, who could approach challenging issues in a rational, objective fashion, and could serve as vehicles for communicating the general pulse of the profession.

Nominees for the Think Tank met one or more of these selection criteria, as evidenced in the supportive information which was submitted with their nominations: 1) significant research on issues germane to user education in academic libraries; 2 ) innovation in educational services on a national or regional level; 3) publication or presentation of theoretical issues contributing to the conceptual development of user education in academic libraries. Every effort was made to identify nine participants who would represent the major issues and concerns in BI-geographically, across the United States and Canada, and experientially, ranging from BI librarians to library directors, to library educators. The perspective of a current library school student was also seen as a desirable element in this process.

\section{Crucial topics in instruction}

Since the group's time together was brief, the program was structured around an opening statement and four working papers. Each was a collaborative effort, prepared in advance by a team of two participants, on four timely topics which will affect the future development of instructional programs in academic libraries:

Opening Statement: "BI Revisited: Do We Need a Facelift? (Do librarians really want one?)," William Miller.

1. "Information Literacy," Hannelore Rader, Bill Coons.

2. "Higher Education Curriculum Reform," Maureen Pastine, Linda Wilson.

3. "The Challenge of Changing User Groups," Betsy Wilson, James Shedlock.

4. "Educating a Second Generation of BI Librarians," Martha Hale, Allison Level, and Elizabeth Frick (in absentia).

With the focus issues identified, each team set out to identify key trends that have surfaced recently in these four areas. Some of the many questions initially posed by the Think Tank Steering Committee included: How should bibliographic instruction programs respond to the challenge that information literacy represents? Is the term information literacy simply rhetoric, or does it have substance? Has the information age caused faculty to radically change the content of their courses, based on the growing realization that they cannot necessarily be expected to know everything on a particular subject? Do remote access information services create a new user population? If so, how can BI respond to their needs? Should current library and information science curricula be changed to accommodate the second generation of BI librarians? Papers were exchanged in advance through fax and the mail.

\section{Think Tank Two unfolds in Dallas}

Think Tank participants met in Dallas, at the Hyatt Hotel, on Thursday evening, June 22. The Thursday session was convened with an informal reception, where participants were able to meet, some for the first time, while others became reacquainted. Betsy Baker provided an overview of the Think Tank, elaborating on its purpose and structure. William Miller set the stage for the Think Tank in his delivery of a provocative assessment of the past directions and developments in BI. The lively conversation from that first session spilled over into a dinner discussion.

On Friday, the Think Tank again met at the 
Hyatt for an all-day session. Participants presented the four working papers. Betsy Baker and Mary Ellen Larson alternated throughout the day in moderating and facilitating the presentations and discussion. As the participants presented their ideas, the moderators assumed a critical devil's advocate role, to test group assumptions and acceptance. Each presentation was followed by brief discussion. Randy Hensley and Beth Sandore recorded notes on highlights of the presentations and the discussion, and presented summaries for the group after each paper, and at the close of the day. In their role as recorders, Hensley and Sandore framed the discussion around new themes that emerged as the Think Tank participants interacted

One of the values of the Think Tank was not just discussion of problems but also the proposing of resolutions and outcomes that directly reflect the concepts discussed by the speakers. For example, in the area of information literacy, such projects that came from the discussion included: development of a continuing education program for BI librarians; publicizing the need to be assertive and political regarding the role of libraries within curricula; development of an information literacy response unit within an organization; and establishment of demonstration sites for initial responses or programs in information literacy; establishment of evaluation criteria.

Throughout the Think Tank, a healthy diversity of opinions was expressed. While participants viewed each subject from different vantage points, three key themes emerged: 1) information literacy: regardless of semantic differences, the group emphasized that it is critical for BI librarians to address broader instructional issues than those contained within the walls of the library, and to make their presence visible on campus, and throughout the user community; 2) the profession must seek new and creative ways to foster the development of new professionals who can ultimately carry the goals of instruction forward; 3 ) the profession should reward leadership, especially when that leadership contributes to innovation, no matter how controversial it may be. As the day wore on, these themes became affectionately known as thousand points of light (no political affiliation suggested), curriculum in the sky, and leaders need love. Our constantly returning emphasis on these themes made it clear to the group that these issues deserve more formal refinement.

\section{Post Think Tank activities}

Think Tank participants and Steering Committee members presented a summary of the work accomplished during this intensive session at the BIS Advisory Council meeting on Saturday, June 24. Written summaries of the Think Tank, com- piled by Hensley and Sandore, were distributed at this meeting. Those interested in obtaining a summary of the Think Tank deliberations may contact Betsy Baker at Northwestern University Library, 1935 Sheridan Rd., Evanston, IL 60201. Plans for a more comprehensive publication including the four working papers are now being pursued.

\section{Toward the future of $\mathrm{BI}$}

As in the past, the Think Tank identified issues which challenge the field in a broad sense, with specific bearing on instructional activities in libraries. BI librarians have constantly been at the forefront in addressing instructional issues throughout the past century. All terminology and aphorisms aside, the Think Tank's purpose involved identifying critical issues facing those involved in some way with $\mathrm{BI}$. One issue which resurfaced continually throughout these discussions was the perception of the degree to which BI, as we now present it, is an integral part of institutions' educational initiatives for the future.

\section{Thanks to Think Tank participants}

The academic library of the 1990s faces a number of issues that affect its role and mission: it must be a leader in the creation, management, and retrieval of electronic information; it must be a designer of information instruction programs; and it must be an interpreter of a generic structure for the communication and dissemination of scholarly information.

The Steering Committee's goal to stimulate a critical look at the educational roles needed by academic research librarians was more than realized by the Think Tank participants. The structure of the Think Tank demanded that each participant examine potentially controversial and in some cases unpopular points of view. The fact that all of the participants were courageous enough to raise these issues and be open to public scrutiny points to their commitment to excellence in growth in the profession.

Some of the issues raised in the Think Tank will certainly benefit from a broader forum within the Bibliographic Instruction Section. To bring others into the discussion, the ACRL BIS Continuing Education Committee is sponsoring a discussion forum entitled, "Information Literacy or Bibliographic Instruction: Semantics or Philosophy?" at the Midwinter Meeting in Chicago, January 1990. Lori Arp, Patricia Breivik, Joan Ormondroyd, and Hannelore Rader will briefly present four viewpoints on the topic that will lead to an informal participatory discussion. Come prepared to voice your questions and concerns in what promises to be a lively and enlightening session. Watch for fliers 
and other publicity announcing the time and place. You are also urged to attend the BIS Think Tank Committee meeting on Sunday morning, January
7, from 9:00-11:00 a.m., if you have any ideas to pass on to the committee.

\section{Installing a local area compact disk}

\section{network}

\author{
By Joan Carey \\ Computer Services Coordinator \\ Brandeis University
}

and Virginia Massey-Burzio

Head of Reader Services

Brandeis University

\section{Patron acceptance of databases on CD-ROM justifies their installation and expense.}

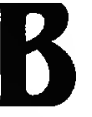

randeis is a small, highly competitive research university. Its two libraries, the Main and Science Libraries, support an undergraduate population of 3,500 students and a graduate student population of approximately 900 . Recently the Main Library (Social Sciences and Humanities) was selected as a test site for the installation of SilverPlatter's MultiPlatter local area network (LAN). The overall reaction to the network has been very enthusiastic.

\section{The CD-ROM network}

On January 26, 1989, the SilverPlatter MultiPlatter system was installed. This is a slightly modified version of CD-Net, developed by Meridian Data Corporation. The basis for the network is Novell Netware zunning over Thin Wire Ethernet. The network server consists of five stacked drives with a 286 processor. Because the server does not have a hard disk drive, access software is mounted on each individual workstation. Our installation was unique in many ways. We were the first to run
MultiPlatter on an Ethernet (Boston College has a Token Ring LAN). We also were the first to use non-uniform hardware. Our current hardware configuration consists of five workstations: one IBM XT, one IBM PC with a hardcard, two Zenith AT compatibles, and one Wyse M310 workstation. The two Zenith stations are equipped with color monitors. Four of these stations are located in the public area near the reference desk. The fifth station, located at the reference desk, is used for a variety of additional functions which include: dialup access to online search vendors like Dialog and BRS; access to other Boston-area online public catalogs; connecting to our campus-wide network; and word processing. All stations are connected to Hewlett-Packard "Thinkjet" printers.

Another unusual aspect of this project was the number and variety of compact disk (CD) products installed. We have ten disks from five different vendors, with only five slots in our server. Therefore, reference staff must "swap" disks on a regular basis. Patrons choose the disk they wish to search from an AutoMenu Screen. A command informs 